\title{
Holistic screening of collapsing honey bee colonies in Spain: a case study
}

\author{
Almudena Cepero ${ }^{1}$, Jorgen Ravoet ${ }^{2}$, Tamara Gómez-Moracho ${ }^{1,3,4}$, José Luis Bernal ${ }^{5}$, Maria J Del Nozal ${ }^{5}$, \\ Carolina Bartolomé ${ }^{3,4,6}$, Xulio Maside ${ }^{3,4,6}$, Aránzazu Meana ${ }^{7}$, Amelia V González-Porto ${ }^{8}$, Dirk C de Graaf², \\ Raquel Martín-Hernández ${ }^{1,9}$ and Mariano Higes ${ }^{1 *}$
}

\begin{abstract}
Background: Here we present a holistic screening of collapsing colonies from three professional apiaries in Spain. Colonies with typical honey bee depopulation symptoms were selected for multiple possible factors to reveal the causes of collapse.

Results: Omnipresent were Nosema ceranae and Lake Sinai Virus. Moderate prevalences were found for Black Queen Cell Virus and trypanosomatids, whereas Deformed Wing Virus, Aphid Lethal Paralysis Virus strain Brookings and neogregarines were rarely detected. Other viruses, Nosema apis, Acarapis woodi and Varroa destructor were not detected. Palinologic study of pollen demonstrated that all colonies were foraging on wild vegetation. Consequently, the pesticide residue analysis was negative for neonicotinoids. The genetic analysis of trypanosomatids GAPDH gene, showed that there is a large genetic distance between Crithidia mellificae ATCC30254, an authenticated cell strain since 1974, and the rest of the presumed C. mellificae sequences obtained in our study or published. This means that the latter group corresponds to a highly differentiated taxon that should be renamed accordingly.

Conclusion: The results of this study demonstrate that the drivers of colony collapse may differ between geographic regions with different environmental conditions, or with different beekeeping and agricultural practices. The role of other pathogens in colony collapse has to bee studied in future, especially trypanosomatids and neogregarines. Beside their pathological effect on honey bees, classification and taxonomy of these protozoan parasites should also be clarified.
\end{abstract}

Keywords: Honeybee, Colony collapse, Viruses, Parasites, Neonicotinoids, Palinology

\section{Background}

The beekeeping sector is suffering unexpected losses in many countries to such extent that pollination services in some cases are jeopardized. Several explanatory 'drivers' are known: an increasing number of pathogens, invasive species, exposure to pesticides, reduced genetic diversity and some apicultural practices. The driver 'pathogens' has received much attention, so scientists have sought for years to find the dangerous mixture of transmittable bee diseases. They often had to face conflicting data and it became increasingly clear that the involved pathogens may vary significantly in different regions.

\footnotetext{
* Correspondence: mhiges@jccm.es

${ }^{1}$ Bee Pathology Laboratory, Consejería de Agricultura, Gobierno de Castilla-La Mancha, Centro Apícola Regional (CAR), Marchamalo E-19180, Spain Full list of author information is available at the end of the article
}

The early detection of Acute Bee Paralysis Virus (ABPV) [1], Chronic Bee Paralysis Virus (CBPV) [2] and Deformed Wing Virus (DWV) [3] in collapsing colonies has determined the experimental design of many subsequent health studies. Later on, the set of target viruses has increased: so, Kashmir Bee Virus (KBV), Black Queen Cell Virus (BQCV) and Sacbrood Virus (SBV) became commonly examined [4]. An unbiased microbiome study aimed at finding the cause of the Colony Collapse Disorder (CCD) in the USA has extended this 'short list' with the Israeli Acute Paralysis Virus (IAPV) and the microsporidian parasite Nosema ceranae [5]. Further investigations either indicate [6,7] or confirmed [8-11] the important role of $N$. ceranae in temperate areas of the world. Very recently, the trypanosomatid Crithidia mellificae was found to be a contributory factor to the colony losses in Belgium [12]. 
The driver 'invasive species' refers mainly to the ectoparasitic mite Varroa destructor. With respect to bee mortality, the Varroa-load seems to be one of the few decisive factors who stand across the borders. In the USA, the small hive beetle (Aethina tumida) seems to be another leading cause of mortality in beekeeping operations [13].

Among proposed causes of bee mortality, the exposure of bees to pesticides received much attention lately and to such extent that the European Commission adopted a proposal [14] to restrict the use of 3 pesticides belonging to the neonicotinoids family (clothianidin, imidacloprid and thiametoxam) for a two years period. However, nationwide monitoring programs of honeybees' exposure level to these crop protection products are rather scarce. Moreover, the real involvement of these pesticides is controversial [15].

Although there is a general agreement that the bee mortality problem is multifactorial $[13,16]$, monitoring programs or case studies that go beyond screening of bee pathogens are rather limited. Besides, the few nationwide studies or clinical studies focusing on pathogens in combination with pesticide residue analysis [17-19] are restricted to the current 'short list' of pathogens (DWV, ABPV, $V$. destructor).

Here we present a holistic screening (a case study) of collapsing honey bee colonies from three professional Spanish apiaries with high colony losses. Colonies with typical depopulation were analysed for the presence of multiple putative drivers of collapse: honey bee viruses, Nosema spp. Varroa destructor, Acarapis woodi, trypanosomatids, neogregarines, neonicotionoid insecticides and foraging flora. This study could also reveal what causal factors should be included in future Spanish monitoring programs [20-28].

\section{Results and discussion}

The most widespread pathogens detected in the analyzed samples were $N$. ceranae and Lake Sinai Virus (LSV), found in all samples (100\%, 10/10). Viruses of the ABPV complex, Acarapis woodi, Nosema apis, CBPV, SBV, SBPV and Varroa destructor were not detected $(0 \%, 0 / 10)$ (Table 1).

The high prevalence $(100 \%)$ of $N$. ceranae in the present study confirmed earlier reports [25,29]. Its ability to evoke the collapse of honey bee colonies and to create the symptoms described by veterinarians (see methods), have been previously reported [10,18,20,30-34]. $N$. ceranae plays a controversial role in the worldwide colony losses phenomenon [16]. While in Mediterranean areas a direct link between this pathogen and the honeybee losses has been reported $[6,8,9,11,30,35,36]$, it can be excluded as main cause of losses in colder areas or continental climates [17,37-39]. Nevertheless, in Belgium it was found that the adverse effects of this microsporidian can be enhanced in combination with the trypanosomatid C. mellificae [12]. In the present study, they were found in 4 samples and 2 apiaries. The three isolates studied (324, 325 and 1980) displayed several haplotypes, with variable levels of intra-isolate diversity (Table 2). Overall, $18 \mathrm{~S}$ rDNA was less variable (pooled total diversity $\pi=0.16 \pm 0.06 \%$; average \pm SE) than GAPDH $(\pi=0.40 \pm 0.14 \%)$ although the difference between both loci was not statistically significant. C. mellificae ATCC30254 also presented multiple haplotypes at the GAPDH locus, which reflects that this reference strain is not isogenic.

The pairwise comparison of the $18 S$ rDNA sequences revealed that $C$. mellificae ATCC30254 (KJ704242 KJ704251) exhibited a single mutation that was not present either in the presumed $C$. mellificae sequences deposited in GenBank (KF607064.1 and AB745488.1) or in ours (KJ704218 - KJ707241). This single difference between $C$. mellificae ATCC30254 and the rest of the sequences is extremely important since any nucleotide variant in a highly conserved marker like the $18 \mathrm{~S} r \mathrm{DNA}$ gene, which displays strong identity (about 99\%) among different genus (Cepero et al., submitted), suggests that C. mellificae ATCC30254 and our sequences (which are mostly identical to KF607064.1 and AB745488.1; Additional file 1: Table S1) might represent genetically isolated organisms.

The analysis of the genetic distances between GAPDH sequences showed that $C$. mellificae ATCC30254 (KJ704273 - KJ704282) displayed a $6.89 \pm 1.32 \%$ divergence with respect to the rest of the sequences, that included both the presumed $C$. mellificae sequences deposited in GenBank (AB716357.1, AB745489.1 and JF423199.1) and ours (KJ704252 - KJ704272), which, again, were in a large fraction identical to AB716357.1 and AB745489.1 (Additional file 2: Table S2). However, this finding is even more surprising if we bear in mind that total divergence estimates, as those calculated here, underestimate the neutral genetic distance between sequences (as replacement sites account for nearly 75\% of the coding sequence and their evolutionary rate is severely limited by purifying selection). Consequently, to obtain more reliable estimates of divergence we performed pairwise comparisons at synonymous sites, which are considered neutral or nearly neutral. The outcome of this analysis is that there is a large genetic distance (23.47 $\pm 5.48 \%$, Table 3) between C. mellificae ATCC30254, an authenticated cell strain since 1974, and the rest of the presumed $C$. mellificae sequences. This means that the latter group corresponds to a highly differentiated taxon that should be renamed accordingly. It is also worth noting the dispersal of Crithidia sp. sequences all over the tree (Figure 1), which questions their current taxonomic classification. In line with this, highly divergent $C$. mellificae lineages were previously mentioned [40]. 
Table 1 Results of the honey bee pathogen (viruses, parasites) screening and pollen analyses (pesticide residue; palynology) on samples from collapsing colonies in Spain

\begin{tabular}{|c|c|c|c|c|c|c|c|c|c|c|c|c|c|c|c|}
\hline \multicolumn{4}{|c|}{ Sample information } & \multicolumn{4}{|c|}{ Viruses } & \multicolumn{8}{|c|}{ Parasites } \\
\hline Sample ID & Apiary & \multicolumn{2}{|c|}{ Location } & BQCV & DWV & LSV & ALPV & \multicolumn{2}{|c|}{ V. destructor } & A. woodi & \multicolumn{2}{|c|}{ Trypanosomatids } & Neogregarines & N. apis & N. ceranae \\
\hline 55 & 1 & Guadal & jara & 0 & 0 & 1 & 0 & 0 & & 0 & & 0 & 0 & 0 & 1 \\
\hline 56 & 1 & Guadal & jara & 0 & 0 & 1 & 0 & 0 & & 0 & & 0 & 0 & 0 & 1 \\
\hline 57 & 1 & Guadal & jara & 0 & 0 & 1 & 0 & 0 & & 0 & & 0 & 0 & 0 & 1 \\
\hline 58 & 1 & Guadal & jara & 1 & 0 & 1 & 0 & 0 & & 0 & & 0 & 0 & 0 & 1 \\
\hline 59 & 1 & Guadal & ajara & 1 & 0 & 1 & 0 & 0 & & 0 & & 0 & 0 & 0 & 1 \\
\hline 1980 & 2 & Vizca & & 1 & 1 & 1 & 1 & 0 & & 0 & & 1 & 0 & 0 & 1 \\
\hline 324 & 3 & Murc & & 1 & 0 & 1 & 0 & 0 & & 0 & & 1 & 1 & 0 & 1 \\
\hline 325 & 3 & Murc & & 1 & 0 & 1 & 1 & 0 & & 0 & & 1 & 0 & 0 & 1 \\
\hline 328 & 3 & Murc & & 0 & 0 & 1 & 0 & 0 & & 0 & & 1 & 0 & 0 & 1 \\
\hline 329 & 3 & Murc & & 0 & 0 & 1 & 0 & 0 & & 0 & & 0 & 0 & 0 & 1 \\
\hline \multicolumn{3}{|c|}{ Sample information } & \multicolumn{10}{|c|}{ Pesticide } & \multicolumn{3}{|c|}{ Palinology } \\
\hline Sample ID & Apiary & Location & Din & efuran & Nitenpyram & Thiametoxa & & Clothianidin & Imidaclopric & & miprid & Thiacloprid & Plant c & us & Source \\
\hline 55 & 1 & Guadalajara & & 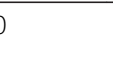 & 0 & 0 & & 0 & 0 & & 0 & 0 & $\begin{array}{l}\text { Thymus, Raphan } \\
\text { Salix, Brassica }\end{array}$ & $\begin{array}{l}\text { Rosmarinus, } \\
\text { orycnium }\end{array}$ & Wild spp. \\
\hline 56 & 1 & Guadalajara & & 0 & 0 & 0 & & 0 & 0 & & 0 & 0 & $\begin{array}{l}\text { Thymus, Raphan } \\
\text { Salix, Brassica }\end{array}$ & $\begin{array}{l}\text { Rosmarinus, } \\
\text { orycnium }\end{array}$ & Wild spp. \\
\hline 57 & 1 & Guadalajara & & b & 0 & 0 & & 0 & 0 & & 0 & 0 & $\begin{array}{l}\text { Thymus, Raphan } \\
\text { Salix, Brassica }\end{array}$ & $\begin{array}{l}\text { Rosmarinus, } \\
\text { orycnium }\end{array}$ & Wild spp. \\
\hline 58 & 1 & Guadalajara & & 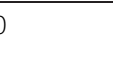 & 0 & 0 & & 0 & 0 & & 0 & 0 & $\begin{array}{l}\text { Thymus, Raphan } \\
\text { Salix, Brassica }\end{array}$ & $\begin{array}{l}\text { Rosmarinus, } \\
\text { orycnium }\end{array}$ & Wild spp. \\
\hline 59 & 1 & Guadalajara & & b & 0 & 0 & & 0 & 0 & & 0 & 0 & $\begin{array}{l}\text { Thymus, Raphan } \\
\text { Salix, Brassica }\end{array}$ & $\begin{array}{l}\text { Rosmarinus, } \\
\text { lorycnium }\end{array}$ & Wild spp. \\
\hline 1980 & 2 & Vizcaya & & 0 & 0 & 0 & & 0 & 0 & & 0 & 0 & Helianthemum, Rap & nus, Rosmarinus & Wild spp. \\
\hline 324 & 3 & Murcia & & 0 & 0 & 0 & & 0 & 0 & & 0 & 0 & Thymus, Cistus, S & $x$, Lavandula & Wild spp. \\
\hline 325 & 3 & Murcia & & 0 & 0 & 0 & & 0 & 0 & & 0 & 0 & Thymus, Cistus, & $x$, Lavandula & Wild spp. \\
\hline 328 & 3 & Murcia & & 0 & 0 & 0 & & 0 & 0 & & 0 & 0 & Thymus, Cistus, S & $x$, Lavandula & Wild spp. \\
\hline 329 & 3 & Murcia & & 0 & 0 & 0 & & 0 & 0 & & 0 & 0 & Thymus, Cistus, S & $x$, Lavandula & Wild spp. \\
\hline
\end{tabular}

$0=$ not detected; 1 = detected. 
Table 2 Estimates of Trypanosomatid diversity at all sites $(\pi)$ expressed as percentage

\begin{tabular}{lccccc}
\hline Isolate & \multicolumn{2}{c}{$18 S \boldsymbol{r D N A}$} & & \multicolumn{2}{c}{ GAPDH } \\
\cline { 2 - 3 } \cline { 5 - 6 } & Average $\boldsymbol{\pi}$ & $\mathrm{SE}$ & & Average $\boldsymbol{\pi}$ & SE \\
\hline ATCC30254 & 0.00 & 0.00 & 0.68 & 0.23 \\
\hline 324 & 0.06 & 0.06 & 0.86 & 0.35 \\
\hline 325 & 0.30 & 0.11 & 0.29 & 0.11 \\
\hline 1980 & 0.08 & 0.08 & 0.39 & 0.16 \\
\hline Pooled & 0.16 & 0.06 & 0.40 & 0.14 \\
\hline
\end{tabular}

SE standard error, calculated by a bootstrap procedure (3000 replicates) with MEGA5.

An unbiased metagenomic study in a Spanish nonprofessional apiary with collapsing colonies revealed the presence of several viruses, among which LSV complex and ALPV strain Brookings [41]. In this study, the former was present in all samples, and the latter in only a few $(20 \%, 2 / 10)$. Sequencing of the LSV amplicons revealed that the strains from apiary 1 and 2 were almost identical (Genbank: KJ561228, KJ561229), but had a low resemblance to the strain from apiary 3 (Genbank: KJ561227). This strain has a high amino acid similarity (89\%) with the Orf1 of LSV strain Navarra (Genbank: AGF84788). So, different LSV strains are present in Spain similar to the situation in Belgium [12] and the USA [40,42]. The pathogenic implications of LSV in honey bee health status are under discussion. Cornman et al. [40] suggested a potential association between LSV and CCD colonies, although this observation was not found in a Belgian bee health screening [12]. In our work, LSV represents the most abundant virus in the analyzed samples collected during spring and summer. For these reason, the importance of LSV and the pathogenicity of different LSV strains should be further investigated.

Black Queen Cell Virus (BQCV) was found in 50\% of samples (5/10) and in all apiaries. This result corresponds with those obtained before [24]. Aphid Lethal Paralysis Virus (ALPV) strain Brookings was found in $20 \%$ of samples $(2 / 10)$ in two apiaries. The amino acid sequences were identical $(>98 \%)$ to those detected previously in Belgium [12], Spain [41] and the USA [42] (Genbank: AGU62863, AGF84786, AEH26191). Curiously, Deformed Wing Virus (DWV) was only detected in one sample in one apiary, and this might be related to the low prevalence of $V$. destructor in the analyzed samples and therefore apiaries.

Neogregarines were detected in one sample. Direct sequencing indicated an infection by Apicystis bombi. However, the presence of overlapping peaks at particular points of the electropherograms suggested a potential mixture of templates, which was further investigated by cloning and sequencing. This process yielded sequences from another Apicomplexan parasite (99\% identity with Eimeriidae or Cryptosporidiidae in Blastn), which was co-infecting the colony with $A$. bombi (whose presence was only confirmed by direct sequencing). Although $A$. bombi was thought to be mainly a bumblebee parasite $[43,44]$, there are increasing findings of that parasite in honey bees [45-47] since a molecular detection method became available [44]. Nevertheless, the amplification of other parasites with the same primers should be taken into account to avoid misdiagnosis in future studies.

Table 3 Pairwise estimates of synonymous substitutions per synonymous site between GAPDH sequences

\begin{tabular}{|c|c|c|c|c|c|c|c|c|c|c|c|c|c|}
\hline & 1 & 2 & 3 & 4 & 5 & 6 & 7 & 8 & 9 & 10 & 11 & 12 & 13 \\
\hline \multicolumn{14}{|l|}{1} \\
\hline 2 & 0 & & & & & & & & & & & & \\
\hline 3 & 0 & 0 & & & & & & & & & & & \\
\hline 4 & 1.58 & 1.58 & 1.58 & & & & & & & & & & \\
\hline 5 & 0 & 0 & 0 & 1.58 & & & & & & & & & \\
\hline 6 & 1.60 & 1.60 & 1.60 & 0 & 1.60 & & & & & & & & \\
\hline 7 & 0 & 0 & 0 & 1.58 & 0 & 1.60 & & & & & & & \\
\hline 8 & 1.58 & 1.58 & 1.58 & 0 & 1.58 & 0 & 1.58 & & & & & & \\
\hline 9 & 0 & 0 & 0 & 1.58 & 0 & 1.60 & 0 & 1.58 & & & & & \\
\hline 10 & 1.60 & 1.60 & 1.60 & 0 & 1.60 & 0 & 1.60 & 0 & 1.60 & & & & \\
\hline 11 & 24.66 & 24.66 & 24.66 & 26.77 & 24.66 & 26.30 & 24.66 & 26.77 & 24.66 & 26.30 & & & \\
\hline 12 & 21.80 & 21.80 & 21.80 & 23.83 & 21.80 & 23.36 & 21.80 & 23.83 & 21.80 & 23.36 & 3.23 & & \\
\hline 13 & 23.21 & 23.21 & 23.21 & 25.29 & 23.21 & 24.81 & 23.21 & 25.29 & 23.21 & 24.81 & 4.34 & 1.06 & \\
\hline 14 & 23.21 & 23.21 & 23.21 & 25.29 & 23.21 & 24.81 & 23.21 & 25.29 & 23.21 & 24.81 & 1.06 & 2.14 & 3.23 \\
\hline
\end{tabular}

1: AB745489.1, 2: AB716357.1, 3: JF423199.1, 4: KJ704252 - 3, 5: KJ704254, 6: KJ704255, 7: KJ704256 - 63, 8: KJ704264, 9: KJ704265 - 69, KJ704271 - 72,10: KJ704270, 11: KJ704273, KJ704275, 12: KJ704274, KJ704281 - 82, 13: KJ704276 - 77, KJ704279, 14: KJ704278, KJ704280. Analyses were conducted in MEGA5 using the Nei-Gojobori model. All positions containing gaps and missing data were eliminated. Comparisons involving ATCC30254 and presumed C. mellificae sequences are highlighted in bold. 


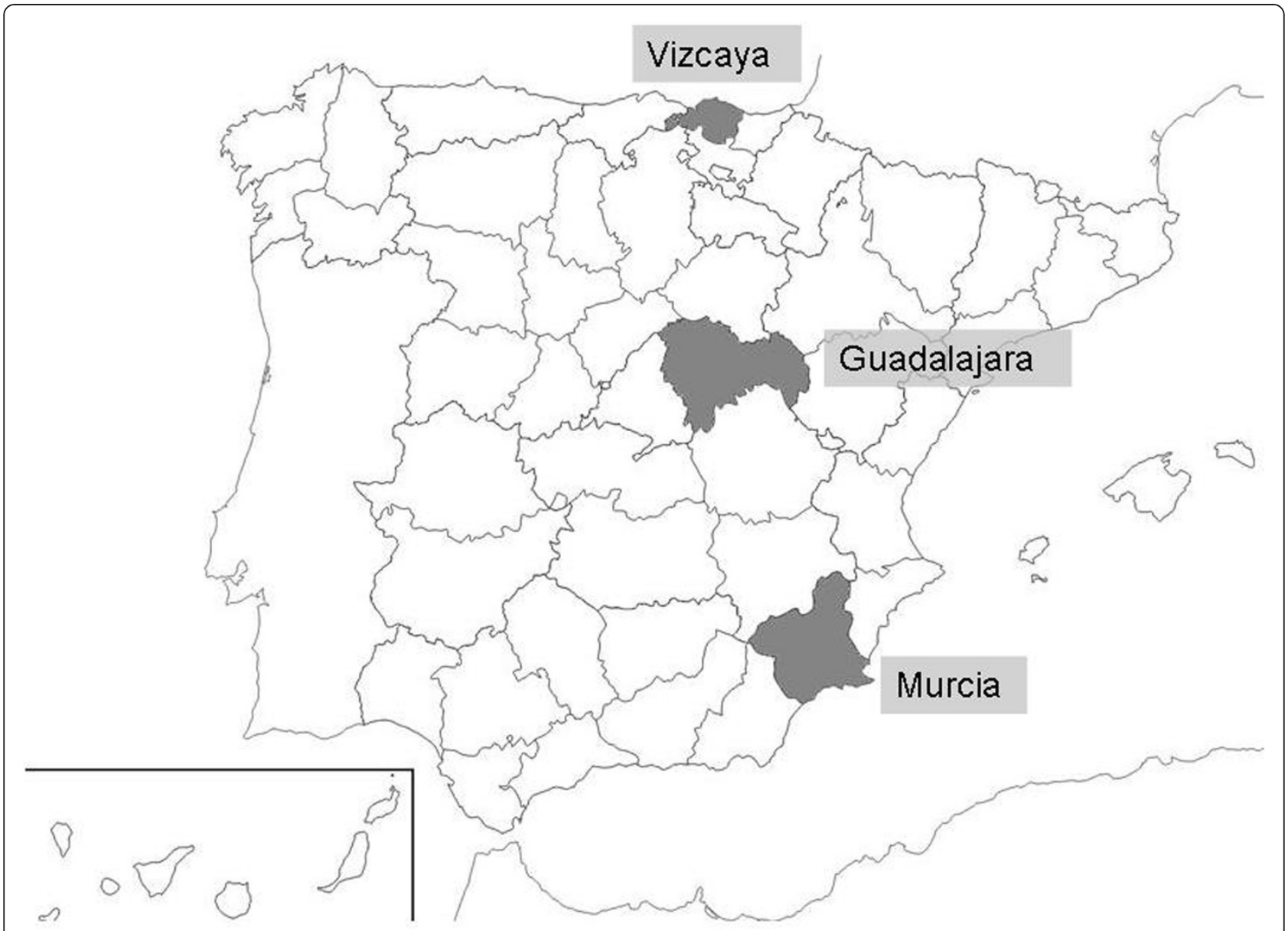

Figure 1 Map of Spain. Provinces of origin of the samples. In the north, Vizcaya. In the central area, Guadalajara. In the southeast, Murcia.

Palinological analyses confirmed that the honeybees foraged on wild plants. As a consequence, no neonicotinoid residues in stored pollen were detected. Although these pesticides exhibited severe acute and sublethal effects on bees [48-50], their role as sole cause of colony loss is still not clear [13,51]. Indeed, most published data have shown that acaricides, herbicides or other insecticide molecules, were more prevalent than neonicotinoids or phenilpirazoles in hives [22,23,52-55]. Our results confirm that neonicotinoids are not the only cause capable of causing the colony collapse of honey bee colonies.

\section{Conclusion}

Many predictive markers and drivers have been suggested for honey bee colony collapses $[5,13,56,57]$. The collapses of honey bee colonies in our study were not related with the presence of neonicotinoids or $V$. destructor. Instead, $N$. ceranae seems to be the main culprit of the colony losses in this study as already suggested in previous investigations $[20,30]$. The role of other pathogens in colony collapse has to be studied in future, especially trypanosomatids and neogregarines. Beside their pathological effect on honey bees, classification and taxonomy of these protozoans also should be clarified. The results of this study clearly demonstrate that the drivers of colony collapse may differ between different geographic regions (see 16, 40).

\section{Methods}

Samples were collected from three professional apiaries each located in a different region of Spain, all under different climatic and environmental conditions (Figure 2). The veterinarians responsible for these apiaries contacted the Centro Apícola Regional (CAR) pathology laboratory, because of alarming symptoms like depopulation and unusually high colony losses.

\section{Apiaries}

Apiary 1: It is located in the Center of Spain in the province of Guadalajara and consisted of 400 bee colonies wintered in 2012, distributed in five apiaries all sited in the same province. In early spring $2013,70 \%$ of the colonies had collapsed, with clear symptoms of depopulation such as disappearance of adult bees and unattended 
brood. Chalkbrood and foulbrood were not reported by the responsible veterinarian. The $30 \%$ of surviving colonies in early spring had a small adult bee population and low vitality. To perform the analysis, 25 weak surviving bee colonies were sampled (worker bees and pollen) in August 2013.

Apiary 2 2: It is located in the province of Vizcaya, Northern Spain. In winter 2012, it had 300 bee colonies distributed in 3 apiaries very closed each other. In early spring 2013, all colonies showed clear signs of depopulation and imminent risk of collapse. The responsible veterinarian has not reported other disease symptoms, although the bee colonies showed a very marked lack of vitality. For analysis, ten collapsing colonies were sampled (worker bees and pollen) in August 2013.

Apiary 3: It is located in the Southeast of Spain, in the province of Murcia. This apiary wintered 175 bee colonies distributed in 4 apiaries in 2011 and the $90 \%$ of them had collapsed in early spring 2012. For the analysis, 16 weak surviving colonies were sampled (worker bees and pollen) in May 2012.

\section{Honey bee sampling}

Samples of worker honey bees ( $\mathrm{n}=100$ worker bees) and stored pollen, were collected from the brood chamber by the veterinarians in charge and sent to the CAR bee Pathology Laboratory in spring (samples from Vizcaya and Murcia) o early summer (samples from Guadalajara). Samples from the apiary 1 ( $n=25$; five per apiary) were pooled together to obtain five pooled samples of five colonies each, one pool sample per apiary. Samples from apiary $2(n=10)$ were pooled into a single sample. Samples for apiary 3 ( $n=16$; four per apiary) were processed as the first apiary so there were four pooled samples from four colonies each (one pooled sample per apiary).

\section{Varroa destructor detection}

The presence of $V$. destructor in worker honey bee samples were analyzed as described previously $[19,20]$.

\section{DNA and RNA extraction}

All bee samples were macerated in AL buffer $50 \%$ (Qiagen) as previously described [24] using sterile bags with filter. Resulting pellets were used for DNA extraction and supernatants for RNA extraction. They were frozen at $-80^{\circ} \mathrm{C}$ until extraction of the nucleic acids.

For DNA extraction, the pellet was resuspended in $3 \mathrm{ml}$ sterile water and $400 \mu \mathrm{l}$ was transferred into a 96-well plate (Qiagen) with glass beads (2 mm diameter, Sigma). Samples were then processed as previously described [25]. Briefly, the plates were shaken for $6 \mathrm{~min}$ at $30 \mathrm{~Hz}$. Afterwards, $150 \mu \mathrm{L}$ of each sample was transferred to a Deepwell plate (Eppendorf) with $30 \mu \mathrm{l}$ of ATL buffer (Qiagen) and $20 \mu \mathrm{l}$ of Proteinase K (Qiagen). After overnight incubation at $56^{\circ} \mathrm{C}$,
DNA was extracted using the BS96 DNA Tissue extraction protocol in a BioSprint machine (Qiagen). Plates were stored at $-20^{\circ} \mathrm{C}$ until use.

RNA was extracted from the supernatant using the DNeasy Blood \& Tissue kit (Qiagen), according to the manufacturer's instructions for RNA isolation. Briefly, $200 \mu \mathrm{l} \mathrm{PBS}$ and $1 \mu \mathrm{l}$ carrier RNA were added to $220 \mu \mathrm{l}$ of the resulting supernatants. After $10 \mathrm{~min}$ incubation at $56^{\circ} \mathrm{C}, 230 \mu \mathrm{l}$ ethanol was added. Subsequent to binding and washing, RNA elution was accomplished with $50 \mu \mathrm{l}$ nuclease-free water.

The C. mellificae reference strain ATCC30254 was included in the analysis for sequence comparison with field isolates. This strain was first cultivated as recommended in ATCC medium 355. Further sub-cultivation was performed in Brain Heart Infusion (BHI) medium as described by Popp and Lattorf [58]. Visible and isolated colonies were taken and resuspended in milliQ water (PCR-quality) and the processed for DNA extraction as above described.

\section{PCR and MLPA analysis}

A broad pathogen screening of the honeybee samples was performed using published PCR assays for Acarapis spp. mites [27], Nosema apis and N. ceranae [25], trypanosomatids and neogregarines [44]. Given that the $18 S$ rDNA gene alone is unsuitable to classify trypanosomatid/s infecting honeybee colonies (Cepero et al., submitted), these were also amplified at the GAPDH locus using CrGD-1 $\mathrm{F}$ (5' GGTCGCCGTGGTGGAC 3') and CrGD-1R (5' CGT CGCCGTGTAGGAGTGA 3'). Since these oligos did not produce an amplicon from ATCC30254, this strain was PCR-amplified with Tryp-1 F (5' CCGAGTACTTCKC STACCAG 3') and Tryp-1R (5' AGCCGAGGATGCC CTTCAT $3^{\prime}$ ), a set of primers that should amplify most Crithidia and Leptomonas species published in GenBank to date. As template, we used $5 \mu \mathrm{DNA}$ in each reaction.

For virus analysis, the BeeDoctor test, a 'multiplexligation probe dependent amplification' (MLPA) based method capable of detecting CBPV, DWV-complex, ABPV-complex, BQCV, SBPV and SBV, was performed as described before [59], starting from $3 \mu \mathrm{l}$ RNA. The amplified MLPA products were analyzed using 4\% high resolution agarose gel electrophoresis.

In addition, we performed additional RT-PCR analyses for few viruses. Using random hexamer primers, $500 \mathrm{ng}$ RNA was retro-transcribed with the RevertAid H Minus First Strand cDNA Synthesis Kit (Thermo Scientific). For ALPV strain Brookings and LSV complex detection, we used $1 \mu \mathrm{l}$ cDNA template in the PCR test described by Runckel et al., [42] and Ravoet et al. [12] respectively.

\section{Sequencing and cloning}

Positive samples of ALPV strain Brookings, LSV complex, trypanosomatids and neogregarines were re-analyzed using 


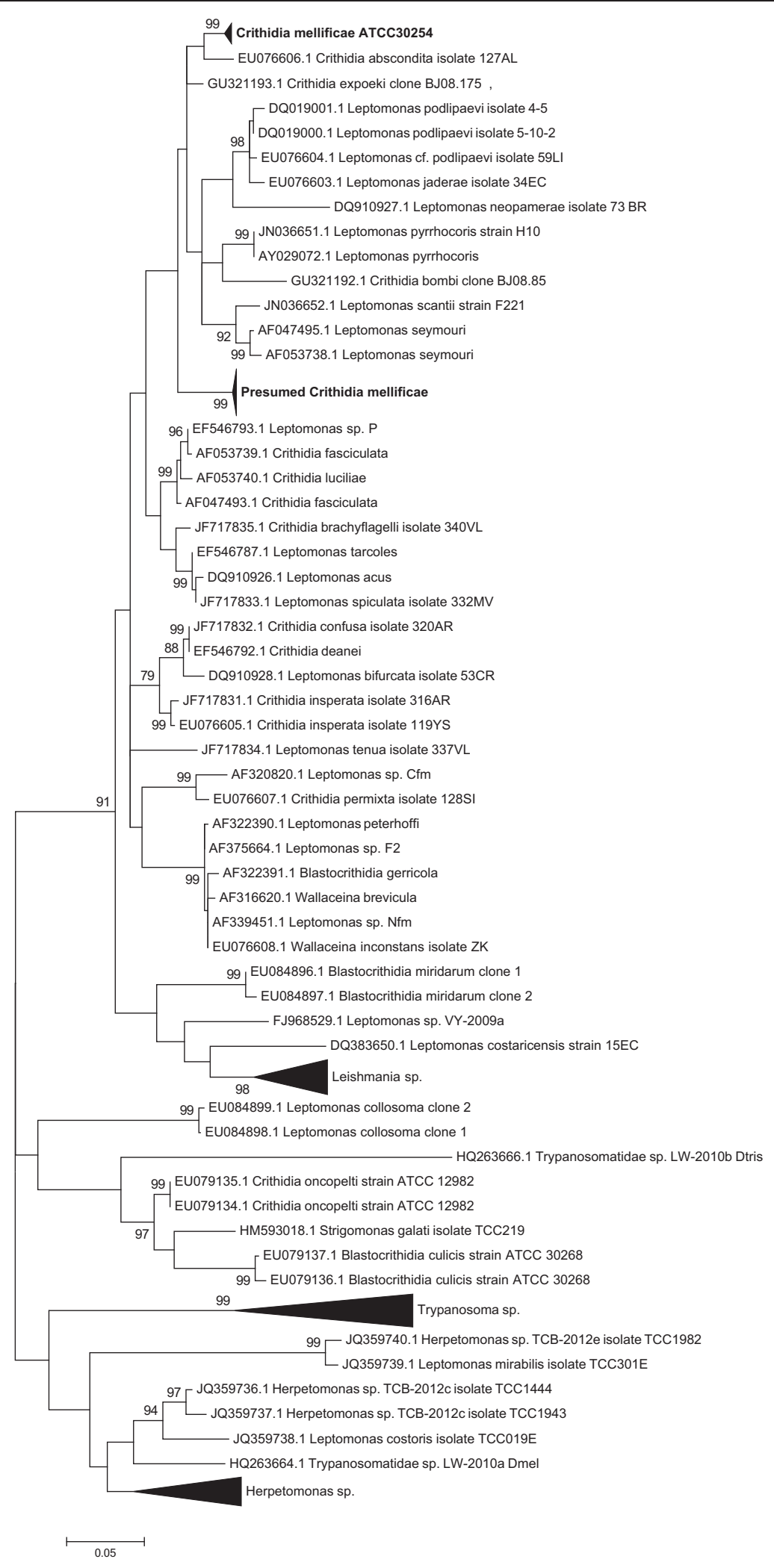

Figure 2 (See legend on next page.) 
the HotStar HiFidelity Polymerase Kit (Qiagen) (viruses) or the Expand High Fidelity ${ }^{\text {PLUS }}$ PCR System (Roche Diagnostics) (protozoans).

Protozoan amplicons were cloned using the Topo TA Cloning Kit (Invitrogen) after purification with the QIAquick PCR Purification Kit (Qiagen). Plasmids were purified using the QIAprep Spin Miniprep Kit (QIAgen). Both strands were sequenced with M13 primers on an automated ABI3730XL sequencer using Big Dye (Applied Biosystems). ALPV strain Brookings and LSV complex amplicons were bidirectional sequenced on an ABI3130XL with gene-specific primers.

Sequences were checked for accurate base calling using CodonCode Aligner (CodonCode Corporation) and their identity verified by means of a nucleotide BLAST. Alignments were manually edited with BioEdit [60] and submitted to GenBank (KJ704218 - KJ704282).

Estimates of overall and pairwise nucleotide diversity were obtained with MEGA v.5.05 [61]. These were measured as $\pi$, applying the Jukes and Cantor (JC) correction [62], and their standard error (SE) calculated by a bootstrap procedure (3000 replicates). This software was also used to construct a maximum likelihood phylogeny under the GTR + G + I model (General Time Reversible + Gamma distributed + Invariable sites) that was selected as best model by applying the Akaike information criterion (AIC), as implemented in MEGA. The reliability of the tree topology was tested by bootstrap support (500 replicates).

\section{Pollen sampling}

In order to obtain a representative pollen samples from each colony, stored pollen ( 3 squares of approximately $10 \times 10 \mathrm{~cm}$ each) collected from the brood chamber combs were extracted aseptically from five colonies of each apiary $[20,22]$. Each pollen sample was divided in two aliquots. One aliquot of $100 \mathrm{~g}$ was used for neonicotinoid screening, while the other aliquot of 5-10 $\mathrm{g}$ was used for palinological analysis. Samples were stored at $-20^{\circ} \mathrm{C}$ until further use.

\section{Neonicotinoids analysis}

Seven neonicotinoid insecticides (acetamiprid, clothianidin, dinotefuran, imidacloprid, nitenpyram, thiacloprid, and thiamethoxam) were analyzed pollen with a previous methodology developed by Yáñez et al. [63]. It should be mentioned that the equipment, methods and reagents were the same than the described in this previous research. The sample treatment consisted of a solid-liquid extraction of the neonicotinoids from pollen with dichloromethane, followed by evaporation and reconstitution. Briefly, $2 \mathrm{~g}$ pollen sample and $10 \mathrm{~mL}$ of dichloromethane were transferred to a centrifuge tube. The mixture was mechanically shaken for $10 \mathrm{~min}$ at 800 oscillations per minute in a Vibromatic and then centrifuged for $10 \mathrm{~min}$ at $25^{\circ} \mathrm{C}$ and $10,400 \times$ g. Following this, the supernatant was collected, filtered through paper filter, transferred to a $25-\mathrm{mL}$ conical flask, and then evaporated until dry in a rotary evaporator at $40^{\circ} \mathrm{C}$. The dry extract was reconstituted with $1 \mathrm{~mL}$ of a water and acetonitrile mixture (50:50, v/v) and the resulting solution was passed through a syringe filter, after which a $15-\mu \mathrm{L}$ aliquot was injected into a liquid chromatograph (LC) coupled to an electrospray ionization mass spectrometry detector (ESI-MS). Once the neonicotinoids were extracted, they were determined using an optimized LC-ESI-MS method, which was validated in terms of selectivity, linearity, precision and recovery. The limits of detection (LOD) and quantification (LOQ) were $0.4-2.8 \mu \mathrm{g} / \mathrm{kg}$ and $1.2-9.1 \mu \mathrm{g} / \mathrm{kg}$, respectively, and the extraction recoveries were between 86 and 106\% in all cases.

\section{Palinological analysis}

The palinological analysis was performed as described previously $[20,22]$. Briefly, pollen grains were isolated from each sample and cleaned up by the Erdtman method [64]. Species identification was performed using a photographic atlas $[65,66]$ and the pollen slides reference collection at the CAR. Briefly, pollen were extracted by diluting $0.5 \mathrm{~g}$ in $10 \mathrm{ml}$ of acidulated water ( $0.5 \%$ sulphuric acid) and then centrifuged at 2,500 rpm for $15 \mathrm{~min}$. The pellet was washed with double-distilled (dd) water, centrifuged and resuspended in ddH2O. $200 \mu \mathrm{l}$ of this suspension was placed onto a glycerin jelly slide and examined microscopically in order to identify the pollen.

\section{Ethics statement}

In Europe, the EU Directive 2010/63/EU on the protection of animals used for scientific purposes laid the down the ethical framework for the use of animals in scientific experiments. The scope of this directive also includes specific invertebrate species, i.e. cephalopods, but no insects. Thus, according to European legislation no specific permits were required for the described studies. 


\section{Additional files}

Additional file 1: Table S1. Pairwise estimates of evolutionary divergence between 185 rDNA sequences (expressed as \%),

Additional file 2: Table S2. Pairwise estimates of evolutionary divergence between GAPDH sequences (expressed as \%).

\section{Competing interests}

None of the authors of this paper has a financial or personal relationship with other people or organizations that could inappropriately influence or bias the content of the paper. The authors declare that they have no competing interests.

\section{Authors' contributions}

$\mathrm{MH}, \mathrm{AM}, \mathrm{RMH}$ and $\mathrm{DCdG}$ designed the study. AC, TG-M, MH, RMH carried out the experimental work of the pathogen analysis and cloning. AVGP carried out the experimental work of the palinological analysis. JLB and MJdN carried out the experimental work of the neonicotinoids analysis. CB and XM carried out the genetic analysis of trypanosomatids and neogregarines. JR carried out the experimental work of the virus analyses. $\mathrm{MH}, \mathrm{CB}, \mathrm{JR}, \mathrm{RMH}$ and $\mathrm{DCdG}$ drafted the manuscript. All authors read and approved the final manuscript.

\section{Acknowledgements}

The authors wish to thanks J. Almagro, J. García, V. Albendea and T. Corrales of the honey bee pathology laboratory for their technical support. This study was supported by the Fund Research Foundation of Flanders (FWO-Vlaanderen G.0628.11), INIA-RTA2013-00042-C10-Subp(03-06), Consejería de Agricultura, Gobierno de Castilla-La Mancha, and MAGRAMA-FEAGA funds (Plan Apícola Nacional 2014)

\section{Author details}

${ }^{1}$ Bee Pathology Laboratory, Consejería de Agricultura, Gobierno de Castilla-La Mancha, Centro Apícola Regional (CAR), Marchamalo E-19180, Spain. ${ }^{2}$ Laboratory of Zoophysiology, Faculty of Sciences, Ghent University, Ghent B-9000, Belgium. ${ }^{3}$ Grupo de Medicina Xenómica, CIMUS, Universidade de Santiago de Compostela, Santiago De Compostela E-15782, Spain.

${ }^{4}$ Xenómica Comparada de Parásitos Humanos, IDIS, Santiago De Compostela, Spain. ${ }^{5}$ Analytical Chemistry Group. I.U.CINQUIMA, Universidad de Valladolid, Valladolid E-47011, Spain. ${ }^{6}$ Departamento de Anatomía Patolóxica e Ciencias Forenses, Universidade de Santiago de Compostela, Santiago De Compostela E-15782, Spain. ${ }^{7}$ Animal Health Department, Facultad de Veterinaria, Universidad Complutense de Madrid, Madrid E-28040, Spain. ${ }^{8}$ Hive Products Laboratory, Consejería de Agricultura. Gobierno de Castilla-La Mancha, Centro Apícola Regional, Marchamalo E-19180, Spain. ${ }^{9}$ Instituto de Recursos Humanos para la Ciencia y la Tecnología (INCRECYT-FEDER), Fundación Parque Científico y Tecnológico de Albacete, Albacete, Spain.

Received: 5 August 2014 Accepted: 5 September 2014 Published: 15 September 2014

\section{References}

1. Ball BV, Allen MF: The prevalence of pathogens in honey bee (apis mellifera) colonies infested with the parasitic mite varroa jacobsoni. Ann Appl Biol 1988, 113:237-244

2. Faucon JP, Mathieu L, Ribiere M, Martel CA, Drajnudel P, Zeggane S, Aurieres C, Aubert MFA: Honey bee winter mortality in France in 1999 and 2000. Bee world 2002, 83:13-23.

3. Nordström S, Fries I, Aarhus A, Hansen H, Korpela S: Virus infections in nordic honey bee colonies with no, low or severe varroa jacobsoni infestations. Apidologie 1999, 30:475-484.

4. Tentcheva D, Gauthier L, Zappulla N, Dainat B, Cousserans F, Colin ME, Bergoin M: Prevalence and seasonal variations of six bee viruses in apis mellifera L. and varroa destructor mite populations in France. Appl Environ Microbiol 2004, 70:7185-7191.

5. Cox-Foster DL, Conlan S, Holmes EC, Palacios G, Evans JD, Moran NA, Quan P-L, Briese T, Hornig M, Geiser DM, Martinson V, VanEngelsdorp D, Kalkstein AL, Drysdale A, Hui J, Zhai J, Cui L, Hutchison SK, Simons JF, Egholm M, Pettis JS, Lipkin WI: A metagenomic survey of microbes in honey bee colony collapse disorder. Science 2007, 318:283-287.
6. Higes M, Martín-Hernández R, Meana A: Nosema ceranae, a new microsporidian parasite in honeybees in Europe. J Invertebr Pathol 2006, 92:93-95.

7. Martín-Hernández R, Meana A, Prieto L, Salvador AM, Garrido-Bailón E, Higes M: Outcome of colonization of Apis mellifera by Nosema ceranae. Appl Environ Microbiol 2007, 73:6331-6338.

8. Hatjina F, Tsoktouridis G, Bouga M, Charistos L, Evangelou V, Avtzis D, Meeus I, Brunain M, Smagghe G, de Graaf DC: Polar tube protein gene diversity among Nosema ceranae strains derived from a Greek honey bee health study. J Invertebr Pathol 2011, 108:131-134.

9. Soroker V, Hetzroni A, Yakobson B, David D, David A, Voet H, Slabezki Y, Efrat H, Levski S, Kamer Y, Klinberg E, Zioni N, Inbar S, Chejanovsky N: Evaluation of colony losses in Israel in relation to the incidence of pathogens and pests. Apidologie 2011, 42:192-199.

10. Villa JD, Bourgeois AL, Danka RG: Negative evidence for effects of genetic origin of bees on Nosema ceranae, positive evidence for effects of Nosema ceranae on bees. Apidologie 2013, 44:511-518.

11. Lodesani M, Costa C, Besana A, Dall'Olio R, Franceschetti S, Tesoriero D, Vaccari G: Impact of control strategies for Varroa destructor on colony survival and health in northern and central regions of Italy. J Apic Res 2014, 53:155-164.

12. Ravoet J, Maharramov J, Meeus I, De Smet L, Wenseleers T, Smagghe G, de Graaf DC: Comprehensive bee pathogen screening in Belgium reveals Crithidia mellificae as a new contributory factor to winter mortality. PLOS One 2013, 8:e72443.

13. VanEngelsdorp D, Meixner MD: A historical review of managed honey bee populations in Europe and the United States and the factors that may affect them. J Invertebr Pathol 2010, 103:80-95.

14. Commission implementing regulation (EU) No 485/2013 of 24 May 2013 amending implementing regulation (EU) No 540/2011. http://eur-lex. europa.eu/LexUriServ/LexUriServ.do?uri=OJ:L:2013:139:0012:0026:EN:PDF, Accessed 12 May 2014

15. Staveley JP, Law SA, Fairbrother A, Menzie CA: A causal analysis of observed declines in managed honey bees (Apis mellifera). Hum Ecol Risk Assess 2014, 20:566-591.

16. Higes M, Meana A, Bartolomé C, Botías C, Martín-Hernández R: Nosema ceranae (microsporidia), a controversial 21 st century honey bee pathogen. Environ Microbiol Rep 2013, 5:17-29.

17. Gisder S, Hedtke K, Möckel N, Frielitz M-C, Linde A, Genersch E: Five-year cohort study of Nosema spp. in Germany: does climate shape virulence and assertiveness of Nosema ceranae? Appl Environ Microbiol 2010, 76:3032-3038

18. Higes M, Martín-Hernández R, Martínez-Salvador A, Garrido-Bailón E, González-Porto AV, Meana A, Bernal JL, Del Nozal MJ, Bernal J: A preliminary study of the epidemiological factors related to honey bee colony loss in Spain. Environ Microbiol Rep 2010, 2:243-250.

19. Garrido-Bailón E: Repercusión Potencial en la Cabaña Apícola Española de Agentes Nosógenos Detectados en Colonias de Apis Mellifera Iberiensis, PhD Thesis. Madrid: Universidad Complutense de Madrid, Departamento de Sanidad Animal; 2012.

20. Higes M, Martín-Hernández R, Garrido-Bailón E, González-Porto AV, GarcíaPalencia P, Meana A, Del Nozal MJ, Mayo R, Bernal JL: Honeybee colony collapse due to nosema ceranae in professional apiaries. Environ Microbiol Rep 2009, 1:110-113.

21. Higes M, Martín-Hernández R, García-Palencia P, Marín P, Meana A: Horizontal transmission of nosema ceranae (microsporidia) from worker honeybees to queens (apis mellifera). Environ Microbiol Rep 2009, 1:495-498.

22. Bernal J, Garrido-Bailón E, Del Nozal MJ, González-Porto AV, Martín-Hernández R, Diego JC, Jiménez JJ, Bernal JL, Higes M: Overview of pesticide residues in stored pollen and their potential effect on bee colony (Apis mellifera) losses in Spain. J Econ Entomol 2010, 103:1964-1971.

23. Bernal J, Martín-Hernández R, Diego JC, Nozal MJ, Gozalez-Porto AV, Bernal JL, Higes M: An exposure study to assess the potential impact of fipronil in treated sunflower seeds on honey bee colony losses in Spain. Pest Manag Sci 2011, 67:1320-1331.

24. Antúnez K, Anido M, Garrido-Bailón E, Botías C, Zunino P, Martínez-Salvador A, Martín-Hernández R, Higes M: Low prevalence of honeybee viruses in Spain during 2006 and 2007. Res Vet Sci 2012, 93:1441-1445.

25. Martín-Hernández R, Botías C, Bailón EG, Martínez-Salvador A, Prieto L, Meana A, Higes M: Microsporidia infecting apis mellifera: coexistence or 
competition. Is nosema ceranae replacing nosema apis? Environ Microbiol 2012, 14:2127-2138.

26. Garrido-Bailón E, Martín-Hernández R, Bernal J, Bernal JL, Martínez-Salvador A Barrios L, Meana A, Higes M: Short communication. The detection of Israeli acute paralysis virus (IAPV), fipronil and imidacloprid in professional apiaries are not related with massive honey bee colony loss in Spain. Spanish J Agric Res 2010, 8:658

27. Garrido-Bailón E, Bartolomé C, Prieto L, Botías C, Martínez-Salvador A Meana A, Martín-Hernández R, Higes M: The prevalence of acarapis woodi in Spanish honey bee (apis mellifera) colonies. Exp Parasitol 2012, 132:530-536

28. Garrido-Bailón E, Higes M, Martínez-Salvador A, Antúnez K, Botías C, Meana A Prieto L, Martín-Hernández R: The prevalence of the honeybee brood pathogens ascosphaera apis, paenibacillus larvae and melissococcus plutonius in Spanish apiaries determined with a new multiplex PCR assay. Microb Biotechnol 2013, 6:731-739.

29. Botías C, Martín-Hernández R, Barrios L, Garrido-Bailón E, Nanetti A, Meana A, Higes M: Nosema spp. parasitization decreases the effectiveness of acaricide strips (Apivar $\left.\left({ }^{(}\right)\right)$in treating varroosis of honey bee (Apis mellifera iberiensis) colonies. Environ Microbiol Rep 2012, 4:57-65.

30. Higes M, Martín-Hernández R, Botías C, Garrido-Bailón E, González-Porto AV, Barrios L, Del Nozal MJ, Bernal JL, Jiménez JJ, García-Palencia P, Meana A: How natural infection by Nosema ceranae causes honeybee colony collapse. Environ Microbiol 2008, 10:2659-2669.

31. Higes M, Martín-Hernández R, Meana A: Nosema ceranae in Europe: an emergent type C nosemosis. Apidologie 2010, 41:375-392.

32. Botías C, Martín-Hernández R, Días J, García-Palencia P, Matabuena M, Juarranz A, Barrios L, Meana A, Nanetti A, Higes M: The effect of induced queen replacement on Nosema spp. infection in honey bee (Apis mellifera iberiensis) colonies. Environ Microbiol 2012, 14:845-859.

33. Botías C, Martín-Hernández R, Barrios L, Meana A, Higes M: Nosema spp. infection and its negative effects on honey bees (Apis mellifera iberiensis) at the colony level. Vet Res 2013, 44:25.

34. Goblirsch M, Huang ZY, Spivak M: Physiological and behavioral changes in honey bees (Apis mellifera) induced by Nosema ceranae infection. PLOS One 2013, 8:e58165.

35. Borneck R, Viry A, Martín-Hernández R, Higes M: Honey bee colony losses in the Jura region, France and related pathogens. J Apic Res 2010, 49:334-336.

36. Bacandritsos N, Granato A, Budge G, Papanastasiou I, Roinioti E, Caldon M, Falcaro C, Gallina A, Mutinelli F: Sudden deaths and colony population decline in Greek honey bee colonies. J Invertebr Pathol 2010, 105:335-340.

37. Stevanovic J, Stanimirovic Z, Genersch E, Kovacevic SR, Ljubenkovic J, Radakovic M, Aleksic N: Dominance of nosema ceranae in honey bees in the Balkan countries in the absence of symptoms of colony collapse disorder. Apidologie 2011, 42:49-58

38. Stevanovic J, Simeunovic P, Gajic B, Lakic N, Radovic D, Fries I, Stanimirovic Z: Characteristics of Nosema ceranae infection in Serbian honey bee colonies. Apidologie 2013, 44:522-536.

39. Hedtke $K$, Jensen PM, Jensen AB, Genersch E: Evidence for emerging parasites and pathogens influencing outbreaks of stress-related diseases like chalkbrood. J Invertebr Pathol 2011, 108:167-173.

40. Cornman RS, Tarpy DR, Chen Y, Jeffreys L, Lopez D, Pettis JS, VanEngelsdorp D, Evans JD: Pathogen webs in collapsing honey bee colonies. PLoS One 2012, 7:e43562.

41. Granberg F, Vicente-Rubiano M, Rubio-Guerri C, Karlsson OE, Kukielka D, Belák S, Sánchez-Vizcaíno JM: Metagenomic detection of viral pathogens in Spanish honeybees: co-infection by aphid lethal paralysis, israel acute paralysis and lake sinai viruses. PLoS One 2013, 8:e57459.

42. Runckel C, Flenniken ML, Engel JC, Ruby JG, Ganem D, Andino R, DeRisi JL: Temporal analysis of the honey bee microbiome reveals four novel viruses and seasonal prevalence of known viruses, Nosema, and Crithidia. PLoS One 2011, 6:e20656

43. Rutrecht ST, Brown MJF: The life-history impact and implications of multiple parasites for bumble bee queens. Int J Parasitol 2008, 38:799-808.

44. Meeus I, de Graaf DC, Jans K, Smagghe G: Multiplex PCR detection of slowly-evolving trypanosomatids and neogregarines in bumblebees using broad-range primers. J Appl Microbiol 2010, 109:107-115.

45. Plischuk S, Meeus I, Smagghe G, Lange CE: Apicystis bombi (apicomplexa: neogregarinorida) parasitizing apis mellifera and bombus terrestris (hymenoptera: apidae) in Argentina. Environ Microbiol Rep 2011, 3:565-568.

46. Maharramov J, Meeus I, Maebe K, Arbetman M, Morales C, Graystock P, Hughes WOH, Plischuk S, Lange CE, de Graaf DC, Zapata N, de La Rosa JJ P, Murray TE, Brown MJF, Smagghe G: Genetic variability of the neogregarine Apicystis bombi, an etiological agent of an emergent bumblebee disease. PLoS One 2013, 8:e81475.

47. Morimoto T, Kojima Y, Yoshiyama M, Kimura K, Yang B, Peng G, Kadowaki T: Molecular detection of protozoan parasites infecting Apis mellifera colonies in Japan. Environ Microbiol Rep 2013, 5:74-77.

48. Desneux N, Decourtye A, Delpuech JM: The sublethal effects of pesticides on beneficial arthropods. Annu Rev Entomol 2007, 52:81-106

49. Belzunces LP, Tchamitchian S, Brunet J-L: Neural effects of insecticides in the honey bee. Apidologie 2012, 43:348-370.

50. Henry M, Béguin M, Requier F, Rollin O, Odoux J-F, Aupinel P, Aptel J, Tchamitchian S, Decourtye A: A common pesticide decreases foraging success and survival in honey bees. Science 2012, 336:348-350.

51. VanEngelsdorp D, Evans JD, Saegerman C, Mullin C, Haubruge E, Nguyen BK, Frazier M, Frazier J, Cox-Foster D, Chen Y, Underwood R, Tarpy DR, Pettis JS: Colony collapse disorder: a descriptive study. PLoS One 2009, 4:e6481.

52. Johnson RM, Ellis MD, Mullin CA, Frazier M: Pesticides and honey bee toxicity - USA. Apidologie 2010, 41:312-331.

53. Mullin CA, Frazier M, Frazier JL, Ashcraft S, Simonds R, VanEngelsdorp D, Pettis JS: High levels of miticides and agrochemicals in North American apiaries: implications for honey bee health. PLoS One 2010, 5:e9754.

54. Lambert O, Piroux M, Puyo S, Thorin C, L'Hostis M, Wiest L, Buleté A, Delbac $F$, Pouliquen $\mathrm{H}$ : Widespread occurrence of chemical residues in beehive matrices from apiaries located in different landscapes of Western France. PLoS One 2013, 8:e67007.

55. Pettis JS, Lichtenberg EM, Andree M, Stitzinger J, Rose R, VanEngelsdorp D: Crop pollination exposes honey bees to pesticides which alters their susceptibility to the gut pathogen Nosema ceranae. PLoS One 2013, 8:e70182.

56. Dainat B, Evans JD, Chen YP, Gauthier L, Neumann P: Predictive markers of honey bee colony collapse. PLoS One 2012, 7:e32151.

57. Farooqui T: A potential link among biogenic amines-based pesticides, learning and memory, and colony collapse disorder: a unique hypothesis. Neurochem Int 2013, 62:122-136.

58. Popp M, Lattorff HMG: A quantitative in vitro cultivation technique to determine cell number and growth rates in strains of crithidia bombi (trypanosomatidae), a parasite of bumblebees. J Eukaryot Microbio/ 2011, 58:7-10.

59. De Smet L, Ravoet J, de Miranda JR, Wenseleers T, Mueller MY, Moritz RFA, de Graaf DC: BeeDoctor, a versatile MLPA-based diagnostic tool for screening bee viruses. PLoS One 2012, 7:e47953.

60. Hall TA: BioEdit: a user-friendly biological sequence alignment editor and analysis program for Windows 95/98/NT. Nucleic Acids Symp Ser 1999, 41:95-98.

61. Tamura K, Peterson D, Peterson N, Stecher G, Nei M, Kumar S: MEGA5: molecular evolutionary genetics analysis using maximum likelihood, evolutionary distance, and maximum parsimony methods. Mol Biol Evol 2011, 28:2731-2739.

62. Jukes TH, Cantor CR: Evolution of Protein Molecules. In Mammalian Protein Metabolism. Volume IIIth edition. Edited by Munro HN. New York: Academic; 1969:21-132.

63. Yáñez KP, Martín MT, Bernal JL, Nozal MJ, Bernal J: Trace analysis of seven neonicotinoid insecticides in bee pollen by solid-liquid extraction and liquid chromatography coupled to electrospray ionization mass spectrometry. Food Anal Methods 2014, 7:490-499.

64. Erdtman G: Handbook of palynology, morphology, taxonomy, ecology: an introduction to the study of pollen grains and spores. Copenhagen, Denmark: Munksgaard; 1969

65. Valdés B: Atlas Polínico de Andalucía Occidental. Sevilla, Spain: Univ Sevilla; 1987.

66. Faegri K, Iversen J: Textbook of Pollen Analysis. 4th edition. Copenhagen Denmark: Munksgaard; 1989.

doi:10.1186/1756-0500-7-649

Cite this article as: Cepero et al.: Holistic screening of collapsing honey bee colonies in Spain: a case study. BMC Research Notes 2014 7:649. 